\title{
Lung volumes of extreme breath-hold divers
}

\author{
Guido Ferretti $\cdot$ Mario Costa $\cdot$ Renato Moroni $\cdot$ Piera Ranieri $\cdot$ Ferdinando Butti $\cdot$ Nicola Sponsiello
}

Received: 15 September 2011 / Accepted: 16 January 2012

(C) Springer-Verlag 2012

\begin{abstract}
Achievements in breath-hold diving depend, amongst others, on body oxygen stores at start of dive. A diver with very high lung volumes could increase dive's duration, and attain deeper depths for a given speed. Thus, we hypothesized that extreme breath-hold divers have very high lung volumes. On eight extreme breathhold divers (age $35+4$ years, height $179+7 \mathrm{~cm}$, body mass $76+6 \mathrm{~kg}$ ) and 9 non-diving controls (age $37+6$ years, height $177+4 \mathrm{~cm}$, body mass $81+9 \mathrm{~kg}$ ) residual volume, vital capacity and total lung capacity (TLC) were
\end{abstract}

Guido Ferretti (凶) · Ferdinando Butti

Dipartimento di Scienze Biomediche e Biotecnologie

Università di Brescia

Viale Europa 11, I-25100 Brescia

e-mail: guido.ferretti@unige.ch

Guido Ferretti

Département des Neurosciences Fondamentales, Université de Genève 1 rue Michel Servet

1211 Genève 4, Switzerland

Mario Costa

Divisione di Anestesiologia, Ospedale Umberto I

Siracusa, Italy

Renato Moroni

Istituto Clinico Città di Brescia, Servizio di Ossigenoterapia Iperbarica Via Gualla 15, Brescia, Italy

Piera Ranieri

Casa di Cura Sant'Anna, Servizio di Broncopneumologia

Unità Operativa di Medicina

Via del Franzone, Brescia, Italy

Nicola Sponsiello

Apnea Academy Research

Padua, Italy measured with a body plethysmograph. Forced vital capacity (FVC) and forced expiratory volume in $1 \mathrm{~s}\left(\mathrm{FEV}_{1}\right)$ were measured with a spirometer. Peak expiratory flow and flow-volume loops were measured with a pneumotachograph. In divers, but not in controls, volumes and capacities were systematically and significantly $(p<0.01$, paired t-test) higher than predicted from their body size. Consistently, volumes and capacities were significantly higher in divers than in controls, except for residual volume. Divers' TLC was $22 \%$ higher than predicted, and $21 \%$ higher than in controls. All divers' TLC was higher than $8 \mathrm{~L}$, two had it higher than $9 \mathrm{~L}$. FVC and $\mathrm{FEV}_{1}$ were significantly higher in divers than in controls. The $\mathrm{FEV}_{1} / \mathrm{FVC}$ ratio was the same in both groups. We conclude that extreme breath-hold divers may constitute a niche population with physiological characteristics different from those of normal individuals, facilitating the achievement of excellent diving performances.

Key words Total lung capacity $\cdot$ Humans $\cdot$ Diving · Adaptation

\section{Introduction}

The duration of a maximal breath-hold dive, and thus the maximal diving depth, are directly proportional to the amount of available aerobic energy stores $\left(\mathrm{EO}_{2}\right)$ in the body at the start of the dive, and inversely proportional to the rate $\left(\mathrm{EO}_{2}\right)$ at which the available aerobic energy stores are consumed. Therefore, from an energetic viewpoint, a diver can improve his performance in three ways: i) reduce the overall rate of energy expenditure; ii) rely on anaerobic metabolism, in order to reduce the fraction of metabolic energy provided by 
aerobic metabolism; iii) increase the amount of $\mathrm{EO}_{2}$. The first approach was pursued by improving the hydrodynamics of a dive and by increasing its mechanical efficiency [1]. The second is made possible by the occurrence of the so-called diving response, originally demonstrated on diving birds and mammals [2], and more recently also in extreme human breath-hold divers [3]. It consists of extreme peripheral vasoconstriction, hypertension, bradycardia and reduced cardiac output. The resulting circulatory cut-off in peripheral tissues, mostly muscles, forces them to rely on anaerobic lactic metabolism, thus reducing $\dot{\mathrm{E}}_{2}$ for any given overall rate of energy expenditure $[4,5]$.

It is generally admitted, however, that $\mathrm{EO}_{2}$ cannot be modified. $\mathrm{EO}_{2}$ has three components: i) tissue oxygen stores, essentially made of oxygen bound to myoglobin; ii) blood oxygen stores, comprising solved oxygen and oxygen bound to hemoglobin; and iii) lung oxygen stores. The first, considered to be constant, corresponds to some $200 \mathrm{ml}$ [6]. The blood oxygen volume depends on hemoglobin concentration, which cannot be acutely increased unless dangerous unethical practices are carried out. Lung oxygen stores are imposed by the oxygen fraction in alveolar air and by the lung volume at the start of dive. To enlarge as much as possible the latter, record dives are performed with a lung volume close to the total lung capacity (TLC). The higher the TLC, the higher would be lung oxygen stores. Respiratory training was found not to increase TLC [7-9], with only one study reporting a slight yet significant TLC increase [10]. However, if a diver had a very high TLC, he would also have proportionately higher lung oxygen stores.

As a reference, the TLC of a healthy adult male European ranges between 5.4 and $7.9 \mathrm{~L}$, depending on body mass, but independent of age and training status [11]. The TLC of Enzo Maiorca from Italy, who was the first man to dive to $100 \mathrm{~m}$ under controlled conditions, was $7.8 \mathrm{~L}$, thus at the uppermost limit of normal population [12]. Mean TLC values higher than these were recently reported on habitual divers [13]. Some case reports, however, mention even higher lung volumes in elite breath-hold divers. On Bob Croft from US, who established a world record to $73 \mathrm{~m}$ in 1968, a TLC of $9.1 \mathrm{~L}$ was found [14]. A TLC above $9 \mathrm{~L}$ was also observed on Francisco Ferreira from Cuba, one of the most performing contemporary breath-hold divers [15]. Anecdotically but coherently, the Greek diver who in 1913 rescued the anchor of an Italian ship that was blocked at a $70 \mathrm{~m}$ depth was described by the ship practitioner as being emphysematous [4], which means that he might have had a very high TLC. Based on these case reports, our hypothesis is that extreme breath-hold divers are characterized by particularly elevated TLC values, well above the uppermost limit of normal population, and consequently may have very large lung oxygen stores. Systematic studies of static and dynamic lung volumes in extreme breath-hold divers, however, were never carried out.

The aim of the present study was to test the hypothesis of high lung oxygen store volume in extreme breathhold divers. To this aim, we measured static and dynamic lung volumes in extreme breath-hold divers, and compared them with those obtained on a group of sex- and age-matched healthy controls.

\section{Subjects and Methods}

Eight male elite breath-hold divers, including world record holder Umberto Pelizzari, participated in the study after having given their informed consent. All had a personal diving record in assisted breath-hold diving of at least 50 $\mathrm{m}$. Their age was $35 \pm 4$ years, their height $179 \pm 7 \mathrm{~cm}$, their body mass $76 \pm 6 \mathrm{~kg}$, and their body surface area, estimated with the formula of Dubois [16], $1.97 \pm 0.12$ $\mathrm{m}^{2}$. A control group of 9 healthy male non-diving subjects (age $37 \pm 6$ years, height $177 \pm 4 \mathrm{~cm}$, body mass $81 \pm$ $9 \mathrm{~kg}$, body surface area $1.99 \pm 0.11 \mathrm{~m}^{2}$ : all values being equal to those observed on divers, as demonstrated by unpaired t-test) was also investigated. The study obtained local ethical approval.

Residual volume (RV), vital capacity (VC) and TLC were measured with a body plethysmograph [17]. Forced vital capacity (FVC) and forced expiratory volume in $1 \mathrm{~s}\left(\mathrm{FEV}_{1}\right)$ were measured with a spirometer. Peak expiratory flow and the expiratory flow-volume curve were computed from the first derivative of the volume - time curve.

\section{Results}

Static lung volumes are presented in Table 1, together with the predicted values, for both divers and controls. In all divers, volumes and capacities were systematically and significantly $(p<0.01$, paired t-test) higher than predicted: this was not the case for the control subjects (NS). Consistently, all volumes and capacities were significantly higher $(p<0.01$, unpaired t-test $)$ in divers than in controls, with the only possible exception of residual volume $(p<0.1)$. All divers had a TLC higher than $8 \mathrm{~L}$. Two of them had a TLC above $9 \mathrm{~L}$. A comparison of TLC values obtained on various diving groups from different sources in the literature is reported in Figure 1. It is noteworthy that extremely high TLC values (above $9 \mathrm{~L}$ ) were found only on three excellent divers, including two world record holders. The remarkably 
Table 1 Static lung volumes in extreme divers and controls

\begin{tabular}{lcccc}
\hline & VC & RV & TLC & RV/TLC \\
\hline DIVERS & & & & \\
measured & 6.64 & 2.12 & 8.76 & 0.24 \\
& 0.53 & 0.41 & 0.63 & 0.04 \\
predicted & 5.35 & 1.88 & 7.23 & \\
& 0.47 & 0.13 & 0.55 & \\
ratio & 1.25 & 1.13 & 1.22 & \\
& 0.17 & 0.18 & 0.10 & \\
CONTROLS & & & & 0.25 \\
measured & 5.42 & 1.84 & 7.26 & 0.03 \\
& 0.61 & 0.33 & 0.83 & \\
predicted & 5.17 & 1.92 & 7.08 & \\
& 0.35 & 0.13 & 0.36 & \\
ratio & 1.05 & 0.96 & 1.03 & \\
& 0.14 & 0.17 & 0.13 & \\
\hline
\end{tabular}

$V C$, Slow vital capacity; $R V$, Residual volume; $T L C$, Total lung capacity. All volumes are expressed in liters BTPS. Data are given as mean and standard deviation. "Measured" designates the values measured in this study; "predicted" designates the values predicted after standard tables. For divers, $n=8$; for controls, $n=9$
Table 2 Dynamic lung volumes in extreme divers and controls

\begin{tabular}{lllc}
\hline & FVC & FEV $_{1}$ & VEMS/FVC \\
\hline DIVERS & & & \\
measured & 6.47 & 5.10 & 0.79 \\
& 0.52 & 0.65 & 0.10 \\
predicted & 5.08 & 4.21 & \\
& 0.41 & 0.32 & \\
ratio & 1.28 & 1.22 & \\
& 0.18 & 0.22 & 0.79 \\
CONTROLS & & & \\
measured & 5.37 & 4.23 & \\
& 0.65 & 0.43 & \\
predicted & 4.89 & 4.05 & \\
& 0.33 & 0.28 & \\
ratio & 1.10 & 1.05 & \\
& 0.15 & 0.14 & \\
\hline
\end{tabular}

$F V C$, Forced vital capacity; FEV1, Forced expiratory volume in one second. All volumes are expressed in liters BTPS. Data are given as mean and standard deviation. "Measured" designates the values measured in this study; "predicted" designates the values predicted after standard tables. For divers, $n=8$; for controls, $n=9$

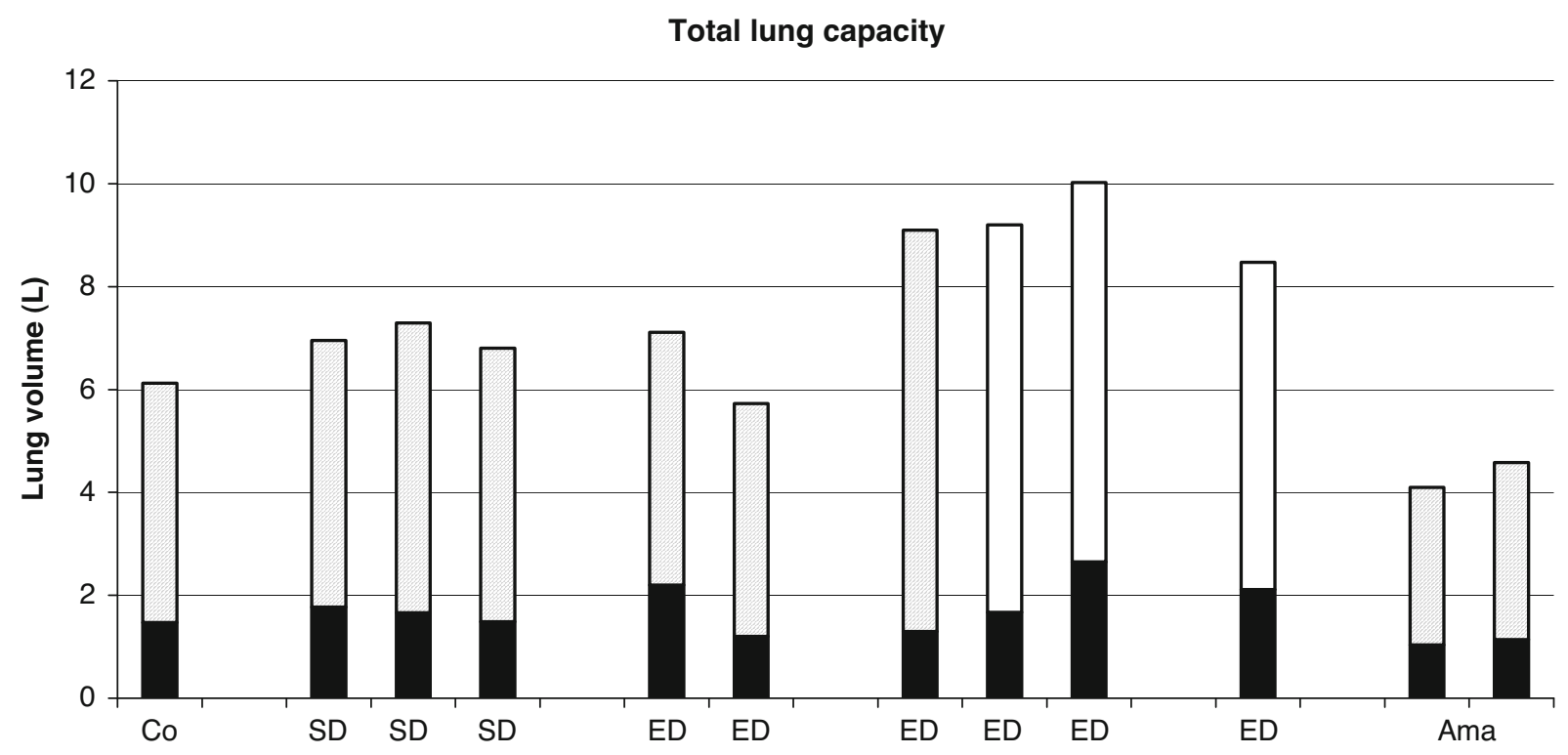

Fig. 1 Comparison of static lung volumes in diving humans from different sources in the literature. Black histograms: residual volume; white histograms, vital capacity from present study, on the two most performing individuals and on average (right), added to the corresponding residual volumes to obtain total lung capacity; dashed histograms: same as white histograms, but from different sources in the literature [12, 14, 15, 18, 24]. Co, control subjects; SD, scuba divers; ED, elite divers; Ama, breath-hold diving women from Korea

high TLC values were essentially due to an increased $\mathrm{VC}$, as little differences were observed as far as the RV is concerned.

Dynamic lung volumes are reported in Table 2 for both divers and controls, and compared with the predicted values from their body mass. Both the FVC and the $\mathrm{FEV}_{1}$ were significantly higher $(p<0.01)$ in divers than in controls. The $\mathrm{FEV}_{1} / \mathrm{FVC}$ ratio was the same in both groups, and was normal in all subjects except one, who showed a slight reduction of $\mathrm{FEV}_{1}$ and of the $\mathrm{FEV}_{1} / \mathrm{FVC}$ ratio.

\section{Discussion}

These results provide clear support to the tested hypothesis that extreme breath-hold divers are characterized by particularly elevated TLC values, well above the uppermost limit of normal population [11], and consequently may have very large lung oxygen stores. The mean TLC value found on the investigated elite divers $(8.76 \mathrm{~L})$ is well above the yet elevated value reported by others on modern habitual divers [13]. These figures 
are compatible with the concept that elite breath-hold divers may indeed constitute a niche population with some physiological characteristics that differ from those of normal individuals and facilitate the achievement of excellent diving performances. In a previous study on three record-breaking breath-hold divers, a diving response, similar to that characteristic of diving mammals, was demonstrated to occur in humans [3]. The subjects of that study, however, were all members of the same family, which let the hypothesis open of peculiar genetic adaptations in them. The subjects of the present study, in contrast, were unrelated, so that the reported lung volume values can indeed be considered representative of a particular group of individuals, significantly different from the average population. The $10.02 \mathrm{~L}$ TLC observed on one diver is the highest TLC value ever reported on an apparently healthy individual, to the best of our knowledge.

The question is open as to whether these particularly high lung volumes are the result of a progressive adaptation to breath-hold diving, analogous to a training effect. Indeed we have no clear answer to this question at present, and the results of this study are not apt to answer it. The occurrence of reversible adaptive phenomena in breath-hold diving populations was demonstrated e.g. in Ama, who lost adaptation to cold when they started using wet suits [5]. Yet Ama did not show increased lung volumes despite their long-lasting diving activity [18, 19], and it is a common notion in exercise physiology that lung volumes cannot be trained [20]. Nevertheless Clanton et al. [21] found a significant increase in VC and TLC in a group of competitive female swimmers, who underwent a specific inspiratory muscle training regimen beside their usual swimming training. The same inspiratory muscle training applied to normal females, however, although it lead to similar increases in maximal inspiratory pressure did not induce lung volume changes [10], so that this training was not held responsible for the changes observed in swimmers. No changes in lung volumes with respect to normal population were found in wind instrument players [7, 9]. Performance of longitudinal studies of lung volumes in breath-hold divers would be helpful in clarifying this aspect.

As high lung volumes as observed on the present subjects are often associated with the occurrence of lung emphysema. Several observations suggest that this may not be the case in extreme divers. Emphysema is generally associated with a larger increase in RV than in other lung volumes, with consequent increase of the RV/TLC ratio: in this study, the RV increase in divers with respect to controls was at the limits of statistical significance, and less than the VC increase (see Table 1), so that the RV/TLC ratio did not differ between the two investigated groups.
Table 3 Effects of lung volumes on alveolar gas composition at the end of simulated dives

\begin{tabular}{ccccc}
\hline $\begin{array}{c}\text { Depth } \\
\mathrm{m}\end{array}$ & $\begin{array}{c}\text { Duration } \\
\mathrm{s}\end{array}$ & $\begin{array}{c}\mathrm{TLC} \\
\mathrm{L}\end{array}$ & $\begin{array}{c}\mathrm{PAO}_{2} \\
\mathrm{mmHg}\end{array}$ & $\begin{array}{c}\mathrm{PACO}_{2} \\
\mathrm{mmHg}\end{array}$ \\
\hline 150 & 220 & 10.0 & 61.2 & 35.6 \\
150 & 220 & 8.8 & 49.9 & 37.3 \\
150 & 220 & 7.3 & 31.1 & 40.3 \\
177 & 258 & 8.8 & 31.4 & 40.2 \\
199 & 288 & 10.0 & 31.8 & 40.2 \\
199 & 288 & 10.0 & 31.8 & 40.2 \\
\hline
\end{tabular}

Bold row, reference values for a subject with a total lung capacity (TLC) of 7.3 L like present controls, who dives to the same depth $(150 \mathrm{~m})$ at the same speed as Pelizzari in his record dive [4]. In the rows above the bold reference row, the effects of changing TLC on $\mathrm{O} 2$ and $\mathrm{CO}_{2}$ partial pressures $\left(\mathrm{PAO}_{2}\right.$ and $\mathrm{PACO}_{2}$, respectively) during a $150 \mathrm{~m}$ are shown, ceteris paribus. In the rows below the bold reference row, the depths theoretically attainable resulting in an alveolar gas composition upon emersion like that of the reference row are shown, ceteris paribus, for different lung volumes. Simulations were made using the average and the highest TLC values observed in this study

Furthermore, the FEV1/FVC ratio was normal, and identical in the two groups, indicating no increase in airway resistance and lack of signs of airway obstruction in divers. Nevertheless, even higher static and dynamic lung volumes were reached in subjects who performed glossopharyngeal breathing manoeuvres [13, $22,23]$. However, it was recently demonstrated that this practice may indeed lead to traumatic lung lesions, eventually resulting in pneumomediastinum or pneumothorax [24].

Very high starting lung volumes are profitable to the success of a deep breath-hold dive [23]. The effects of increasing the starting lung volume on the alveolar gas composition at the end of extreme breath-hold dives were analyzed on a computer simulation [4]. The results are reported in Table 3. At emersion from a dive to $150 \mathrm{~m}$, performed in a given time and with the same metabolic rate, alveolar $\mathrm{PO}_{2}$ turns out higher and alveolar $\mathrm{PCO}_{2}$ lower, the larger the TLC. Moreover, the larger the TLC, the deeper and longer would be the dive resulting in a given predetermined alveolar gas composition at emersion. This is because, for a given alveolar oxygen fraction (or pressure), the volume of oxygen contained in the alveoli at the start of a dive is directly proportional to the individual TLC. For instance, a diver with a TLC of $9 \mathrm{~L}$ instead of 7.8, he would have had at the start of a dive $15 \%$ larger lung oxygen stores, allowing him to reach, ceteris paribus, proportionately greater depths.

The results of this simulation suggest that a diver with the same TLC as the highest value found in this study, who dives with the same technique and speed as Pelizzari in his record dive could eventually reach a depth of $200 \mathrm{~m}$ and still emerge conscious. Such a dive, however, would be very 
risky, since the resulting alveolar gas composition, when plotted on an $\mathrm{O}_{2}-\mathrm{CO}_{2}$ diagram [25], would be close to the region of anoxic collapse, well beyond the apnea breaking curve [12]. No margins for mistakes would be allowed: a $5 \%$ increase in the overall rate of energy expenditure would suffice to induce loss of consciousness in the last $20 \mathrm{~m}$ of ascension.

The ultimate aim of an extreme breath-hold diver is to dive deeper still emerging conscious. This aim was pursued essentially by increasing the diving speed (v). For example, both the record dive to $100 \mathrm{~m}$ by Enzo Maiorca from Italy and that to $150 \mathrm{~m}$ by Umberto Pelizzari, also from Italy, lasted $3.5 \mathrm{~min}$. Therefore, the latter deeper dive was carried out at an average speed some $50 \%$ faster than the former (assuming immediate ascension from bottom, $1.43 \mathrm{~m} \mathrm{~s}-1$ instead of $0.95 \mathrm{~m} \mathrm{~s}-1)$ [4]. The $\mathrm{v}$ is directly proportional to the rate of energy expenditure $(\dot{\mathrm{E}})$ and inversely proportional to the energy cost of diving (C) En

$$
\mathrm{v}=\dot{\mathrm{E}} / \mathrm{C}
$$

$\mathrm{C}$ in turn is equal to:

$$
\mathrm{C}=\mathrm{D} / \eta
$$

where $\mathrm{D}$ is the drag, i. e. the force opposing the movement of a body in water, which depends on the water resistance and on the buoyancy of the body, and $\eta$ is the mechanical efficiency of movement. An increase in $\mathrm{v}$ was achieved through a reduction of $\mathrm{C}$, which implies either a reduction of $\mathrm{D}$, or an improvement of $\eta$, or both. Hydrodynamic research helps to lower D, especially through a decrease in the drag coefficient [1]. The pursuit of better diving techniques, limiting useless movements and reducing internal work, may help to improve $\eta$.

Acknowledgements Financial support was provided by National Science Foundation, Switzerland, and Ministry of Instruction and Research, Italy. The cooperation of Umberto Pelizzari and Stefano Tovaglieri from Apnea Academy is acknowledged. We thank Carmen Espinosa for technical support in performing this study.

\section{Conflict of interest statement None.}

\section{References}

1. Pendergast DR (1987) Energetics of breath-hold diving. In: The Physiology of Breath-Hold Diving. Lundgren CEG, Ferrigno M eds. Undersea and Hyperbaric Medicine Society, Bethesda, MD, pp 135-147

2. Andersen, HT (1966) Physiological adaptations in diving vertebrates. Physiol Rev 46:212-243

3. Ferrigno M, Ferretti G, Ellis A et al (1997) Cardiovascular changes during deep breath-hold dives in a pressure chamber. J Appl Physiol 83:1282-1290
4. Ferretti G (2001) Extreme human breath-hold diving. Eur J Appl Physiol 84:254-271

5. Ferretti G, Costa M (2003) Diversity in and adaptation to breathhold diving in humans. Comp Biochem Physiol 136(A):205-213

6. Rahn $\mathrm{H}$ (1987) Breath-hold diving: alveolar $\mathrm{O}_{2}$ and blackout. In: Underwater and Hyperbaric Physiology IX. Bove AA, Bachrach AJ, Greenbaum LJ eds. Undersea and Hyperbaric Medicine Society, Bethesda MD, pp 3-15

7. Bouhuys A (1964) Lung volumes and breathing patterns in windinstrument players. J Appl Physiol 19:967-975

8. Danuser HJ, Buhlmann AA (1983) Effect of regular training on total and vital capacity of the lung in 17 to 25 -year-old rowers. Schweiz Med Wochenschr 113:454-458

9. Schorr-Lesnick B, Teirstein AS, Brown LK, Miller A (1985) Pulmonary function in singers and wind-instrument players. Chest 88:201-205

10. Clanton TL, Dixon GF, Drake J, Gadek JE (1985) Inspiratory muscle conditioning using a threshold loading device. Chest 87:62-66

11. Jouasset D (1960) Normalisation des épreuves fonctionnelles respiratoires dans les pays de la Communauté Européenne du Charbon et de l'Acier. Poumon Coeur 10:1145-1159

12. Ferretti G, Costa M, Ferrigno M et al (1991) Alveolar gas composition and exchange during deep breath-hold diving and dry breath holds in elite divers. J Appl Physiol 70:794-802

13. Seccombe LM, Rogers PG, Mai N et al (2006) Features of glossopharyngeal breathing in breath-hold divers. J Appl Physiol 101:799-801

14. Schaefer KE, Allison RD, Dougherty JH jr et al (1968) Pulmonary and circulatory adjustments determining the limits of depth in breath-hold diving. Science 162:1020-1023

15. Ferrigno M, Lundgren CEG (1999) Human breath-hold diving. In: The Lung at Depth. Lundgren CEG, Miller J, Eds. Dekker, New York, pp 529-585

16. Dubois D, Dubois EF (1916) A formula to estimate the approximate surface area if height and weight be known. Arch Int Med 17:863-871

17. Dubois AB, Botelho SY, Bedell GN et al (1956) A rapid plethysmographic method for measuring thoracic gas volume: a comparison with a nitrogen washout method for measuring functional residual capacity in normal subjects. J Clin Invest 35:322-326

18. Hong SK, Rahn H, Kang DH et al (1963) Diving pattern, lung volumes, and alveolar gas of the Korean diving women (ama). J Appl Physiol 18:457-465

19. Song SH, Kang DH, Kang BS, Hong SH (1963) Lung volumes and ventilatory responses to high $\mathrm{CO}_{2}$ and low $\mathrm{O}_{2}$ in the ama. $\mathrm{J}$ Appl Physiol 18:466-470

20. Åstrand, PO, Rodahl K (1986) Textbook of Work Physiology. McGraw Hill, New York

21. Clanton TL, Dixon GF, Drake J, Gadek JE (1987) Effects of swim training on lung volumes and inspiratory muscle conditioning. J Appl Physiol 62:39-46

22. Lemaître F, Clua E, Andréani B et al (2010) Ventilatory function in breath-hold divers: effect of glossopharyngeal insufflation. Eur J Appl Physiol 108:741-747

23. Overgaard K, Friis S, Pedersen RB, Lykkeboe G (2006) Influence of lung volume, glossopharyngeal inhalation and $\mathrm{P}(\mathrm{ET}) \mathrm{O}_{2}$ and $\mathrm{P}(\mathrm{ET}) \mathrm{CO}_{2}$ on apnea performance in trained breath-hold divers. Eur J Appl Physiol 97:158-164

24. Chung SC, Seccombe LM, Jenkins CR et al (2010) Glossopharyngeal insufflation causes lung injury in trained breath-hold divers. Respirology 15:813-817

25. Rahn H, Fenn WO (1955) A Graphical Analysis of the Respiratory Gas Exchange. The $\mathrm{O}_{2}-\mathrm{CO}_{2}$ Diagram. American Physiological Society, Washington, DC 